\title{
Relationship between Helicobacter pylori Adenotonsillar Colonization and Frequency of Adenotonsillitis in Children
}

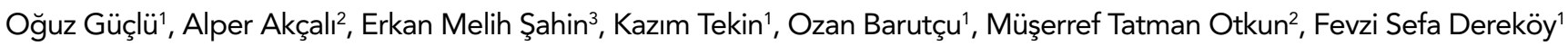 \\ 'Department of Otolaryngology, Çanakkale Onsekiz Mart University, Çanakkale, Turkey \\ ${ }^{2}$ Department of Medical Microbiology, Çanakkale Onsekiz Mart University, Çanakkale, Turkey \\ ${ }^{3}$ Department of Family Medicine, Çanakkale Onsekiz Mart University, Çanakkale, Turkey
}

\begin{abstract}
Background: There are insufficient data in the literature on the presence of Helicobacter pylori in tonsil and adenoid tissue of patients with only airway obstruction. This study examined the presence of $H$. pylori in surgical cases with airway obstruction or recurrent infection.
\end{abstract}

Aims: To investigate the relationship between $\mathrm{H}$. pylori adenotonsillar colonisation and the frequency of adenotonsillitis and to compare paediatric and adult patients according to $H$. pylori tonsillar colonisation.

Study Design: Prospective clinical trial.

Methods: Patients scheduled for adenoidectomy or tonsillectomy were classified into three groups based on indications: paediatric infection ( $\mathrm{n}=29$ ), paediatric obstruction $(n=29)$ and adult infection $(n=12)$. Tissue samples obtained from patients were examined for the presence of $H$. pylori by culture, rapid urease test and polymerase chain reaction.

Results: Forty-nine tonsil tissues were examined. Positive results were found in two specimens with the rapid urease test (4.1\%) and three with polymerase chain reaction examination (6.1\%). Only three positive polymerase chain reaction results (5.8\%) were identified in 52 adenoid tissue samples. There were no statistically significant differences in the presence of $\mathrm{H}$. pylori between paediatric infection and obstruction groups or between paediatric infection and adult infection groups.

Conclusion: In our study, there was a low incidence of $H$. pylori colonisation in tonsil and adenoid tissues. Regarding $H$. pylori colonisation, there was no significant difference between paediatric infection and obstruction groups. Also, no significant difference was found between adult and paediatric cases.

Key Words: Helicobacter pylori, adenoid, tonsil, colonisation, frequency of infection, PCR

Received: 23.12.2012 Accepted: 12.04.2013

\section{Introduction}

Helicobacter pylori is a Gram-negative microaerophilic bacterium persistently found in gastric mucosa. It may be the most frequent chronic infection affecting humans, with over half of the world's population infected (1). Recent studies are available showing $H$. pylori colonisation in adenoid and tonsil tissue (2-4). However, as shown by studies in the literature, this topic is debated (1,5-6). Adenoidectomy and tonsillectomy are frequently applied surgical interventions, especially in paediatric age groups. Recurrent infections and airway obstruction are the most frequent indications for surgery. Tonsil and adenoid hypertrophy may simply cause obstruction or may be observed with recurrent infections. There are insufficient data in the literature on the presence of $H$. pylori in cases with only airway obstruction. This study examined the presence of $H$. pylori in surgical cases with airway obstruction or recurrent infection. The aim was to clearly define the between recurrent adenotonsillitis and $\mathrm{H}$. pylori adenotonsillar colonisation. Another aim was to investigate differences in the presence of tonsillar $H$. pylori in paediatric and adult patients with recurrent tonsillitis.

\section{Material and Methods}

The study was conducted at the Otorhinolaryngology Department and Clinical Microbiology Department of Çanakkale Onsekiz Mart University, Faculty of Medicine. It was approved by the local Ethics Committee. Patients attending the Otorhinolaryngology Department who had elected to undergo surgery for adenotonsillar pathology were included in the study. Tissue samples taken from these patients during surgery were examined for the presence of $H$. pylori.

Patients were classified based on indications for surgery. Three groups were formed: paediatric obstruction - children with adenotonsillar hypertrophy; paediatric infection - children with recurrent adenotonsillitis; and adult infection adults with recurrent tonsillitis. Patients without a frequent infection history and with obstructive adenoid and tonsillar hypertrophy determined by diagnostic nasal endoscopy and oropharyngeal examination were placed in the obstruction group. On examination, patients with adenoids covering more than $75 \%$ of the choana and grade 3-4 tonsillar hypertrophy were included in this group (7). Frequent infections 
were defined as three or more attacks in a year. In addition, patients receiving antibiotic treatment in the month before operation were excluded from the study.

Operations were conducted under general anaesthesia. Midazolam (Dormicum, Roche, Germany) was given in the preoperative period for sedation. Before the adenotonsillectomy, biopsies were taken using a direct punch forceps. A sample of tissue was taken from the right or left tonsil. Samples were brought to the microbiology laboratory in brain heart infusion broth. Immediately the samples were separated into small pieces using sterile scalpel blades under sterile conditions. For each separate sample, one piece was placed on a Campylobacter-like organism (CLO) test card (Rapid Urease Test; Kimberly-Clark Roswell, USA). This test was examined visually after $20 \mathrm{~min}$ and $24 \mathrm{~h}$ at room temperature, and a red-pink colour change was accepted as positive. One part of each tissue sample was streaked onto a pylori agar plate (BioMérieux, Marcy l'Etoile, France) and incubated at $36^{\circ} \mathrm{C}$ in a jar with Anaerocult $\mathrm{C}$ microaerophilic atmosphere kit (Merck, Darmstadt, Germany). Plates were checked on the third and seventh day for microbial growth. Suspicious colonies were evaluated with Gram stain, urea hydrolysis and oxidase tests. The remaining pieces of tissue sample were stored in liquid medium in deep freeze tubes at $-80^{\circ} \mathrm{C}$ for polymerase chain reaction testing. $H$. pylori NCTC 11637 strain was used as a positive control.

Polymerase chain reactions (PCR) were completed using the following steps:

1. Samples were brought to room temperature before use. In a sterile Petri dish, using a sterile scalpel blade, the sample was divided into very small pieces and homogenised. Volumes of $8-10 \mathrm{~mm}^{3}$ of tissue sample were placed in sterile tubes, then $100 \mu \mathrm{L}$ tissue digestion buffer (Heliosis, Metis Biotechnology, Ankara, Turkey) was added and left for $3 \mathrm{~h}$ at $65^{\circ} \mathrm{C}$. After $10 \mathrm{~min}$ at $95^{\circ} \mathrm{C}$, the tube was centrifuged at $10000 \mathrm{rpm}$ and the supernatant was used for DNA extraction.

2. The extraction was completed using a Heliosis DNA extraction module (Metis Biotechnology, Ankara, Turkey) according to the manufacturer's guidelines.

3. The PCR was completed with a Helicobacter pylori DNA $23 \mathrm{~S}$ kit (Metis Biotechnology, Ankara, Turkey) following the manufacturer's guidelines. The test works on the principle of nested PCR, with a series of outer and later inner primers with two consecutive PCR runs. The PCRs were performed with a Mastercycler gradient (Eppendorf, Hamburg, Germany) thermal cycler device.

4. The reaction products were inspected on $3 \%$ agarose gel, after electrophoresis ( $20 \mathrm{~min} ; 75 \mathrm{~V}$ ), and examined for a 96 base pair product.

All PCR steps were carried out in separate rooms to prevent contamination. In each study, positive and negative mixtures were prepared and if appropriate results were obtained, the tests were evaluated. Positive samples were confirmed by repeating studies on extraction products.

SPSS ${ }^{2} 20$ program was used for statistical analysis. Means and standard deviations of groups were calculated. Fisher's exact test was used to determine significant differences be- tween non-parametric data from the groups. The results were evaluated at a significance level of $p<0.05$.

\section{Results}

Seventy patients (39 male, 31 female) were included in the study. Twenty-nine patients were in the paediatric obstruction group (average age $8.25 \pm 3.15$ years), 29 in the paediatric infection group (7.28 \pm 3.01 years) and 12 patients in the adult infection group (29.92 \pm 8.44 years). In paediatric cases, adenotonsillectomy was performed in 31 patients, adenoidectomy alone in 21 patients and tonsillectomy alone in six patients. In addition, we performed tonsillectomy on 12 adult patients.

In the paediatric cases, we investigated 89 adenoid and tonsil samples. We found five positive (6\%) PCR results, two samples in the obstruction group and three samples in the infection group (Table 1). We did not find a statistically significant difference between the infection and obstruction groups.

Tonsil samples from a total of 49 patients were examined. There was no $H$. pylori growth in any tonsil culture. A positive CLO test was found for two patients (4.1\%). Positive PCR results were determined for three cases (6.1\%). There was no statistically significant difference between PCR results from the obstruction and paediatric infection groups $(p=0.393)$. Additionally, there was no statistically significant difference between the paediatric and adult infection groups in terms of PCR results from tonsil samples $(p=0.747$, Table 2$)$.

Fifty-two adenoid samples were examined. There was no $H$. pylori growth or positive CLO test results in these samples. Only three positive PCR results (5.8\%) were identified. Two of them were in the paediatric obstruction group and other one was in the paediatric infection group. There was no statistically significant difference between the obstruction and paediatric infection groups in terms of PCR results from adenoid samples $(p=0.559)$.

Table 1. PCR detection of Helicobacter pylori in tonsil and adenoid specimens: paediatric infection group versus paediatric obstruction group

\begin{tabular}{|lcc|}
\hline & \multicolumn{2}{c|}{ Tonsil and Adenoid PCR Results } \\
\cline { 2 - 3 } & Negative & Positive \\
\hline Paediatric obstruction & 38 & 2 \\
Paediatric infection & 46 & 3 \\
\hline PCR: Polymerase chain reactions & \\
\hline
\end{tabular}

Table 2. PCR detection of Helicobacter pylori in tonsil specimens: paediatric infection group versus adult infection group

\begin{tabular}{|lcc|}
\hline & \multicolumn{2}{c|}{ Tonsil PCR Results } \\
\cline { 2 - 3 } & Negative & Positive \\
\hline Paediatric infection & 22 & 2 \\
Adult infection & 11 & 1 \\
\hline
\end{tabular}

*Fisher's Exact Test, $p=0.747$, PCR: Polymerase chain reactions 


\section{Discussion}

Helicobacter pylori is a Gram-negative, microaerophilic bacterium and, after its initial discovery in 1983, it was shown to have a clear relationship to gastritis, peptic ulcers and low grade MALT lymphomas (2). It is known to be present in the oropharyngeal area in subgingival plaques, dental plaques and saliva (1). In recent years, research has shown its presence in middle ear effusions and tonsil and adenoid tissues $(8,9)$.

Factors that affect $H$. pylori colonisation include socioeconomic circumstances, genetic characteristics of the bacteria and patient, the presence of accompanying infection and the use of antibiotics (2). In addition to these, a study in 1998 on tonsillectomy patients showed a reduction in gastric colonisation and speculated that tonsil tissue may act as a reservoir for $H$. pylori (10). At this point, another question came to mind: does $H$. pylori colonisation have an effect on the frequency of tonsil and adenoid infections? In order to clarify this point, our study investigated the difference in $H$. pylori colonisation between paediatric patients subject to frequent infections and those suffering only from obstruction. Culture, CLO test and PCR were used to investigate the presence of $H$. pylori. There was no significant difference between the two groups and our results essentially support the view that there is no relationship between infection frequency and $\mathrm{H}$. pylori colonisation. A study of similar design was carried out by Lin et al. (2) in 2010. They found a difference in $\mathrm{H}$. pylori colonisation in adult patients suffering from recurrent tonsillar infections and those suffering from basic hyperplastic tonsil tissues (a sleep-related breathing disorder). However, Lin et al.'s study was performed on adult patients and it is inappropriate to extend these results to paediatric cases. Our study also compared paediatric and adult cases of recurrent tonsillar infections. There was no significant difference between the groups in terms of PCR results for $H$. pylori. However, $H$. pylori positive results were low in our groups and it may not be accurate to generalise from these results.

There is a wide range of results reported from various studies on the incidence of $H$. pylori colonisation in adenoid and tonsillar tissues. Unver et al. (11) reported $57.9 \%$ positive CLO tests on samples from 19 patients who underwent adenotonsillectomy. In a study of tonsil and adenoid tissue from 23 patients, Cirak et al. (3) found $30 \%$ positive PCR results for the presence of $H$. pylori. These studies support $H$. pylori colonisation in tonsil and adenoid tissue. However, studies showing no significant $H$. pylori colonisation are also available. In a study of 139 specimens, Jelavic et al. (5) determined that $12 \%$ had $H$. pylori present using the rapid urease test (RUT). Eyigor et al. (4) found three samples (5.5\%) from 35 adenoid and 20 tonsil samples with positive CLO tests. The same study found no positive results from PCR investigations. In a study of 101 surgical specimens, Vilarinho et al. (1) found no positive results with PCR-DEIA tests. In our study, there was no positive growth in culture, and only two samples (2\%) gave positive RUT results. A total of six specimens $(5.9 \%)$ gave a positive PCR result.

False positive results from RUT are known from the literature (1). However, RUT is not actually a specific test for
H. pylori and simply shows the presence of microorganisms with urease activity. Also, RUT is a more appropriate test for samples taken from the gastric region. Other microorganisms from the oropharyngeal area with urease activity may give a false positive result. In a similar manner, microorganisms with urease activity such as Klebsiella spp. and Proteus spp. have given false positive results in samples from the stomachs of achlorhydric patients, as reported by Bitar et al. (12). In conclusion, a high number of positive results from RUT on adenoid and tonsil tissues may be due to bacteria other than $H$. pylori.

We found a low incidence of $H$. pylori colonisation in tissue samples. In a study on the prevalence of $H$. pylori infection in healthy paediatric patients in our country, Yilmaz et al. (13) found $43 \%$ seropositivity. However, regional data are still lacking and the $H$. pylori frequency in our area of study may have affected our results. Samples for the study were taken with punch forceps at the start of the operation. As a result, this reduced the chances of contamination from oropharyngeal mucosa during the operations.

In conclusion, this study found a low incidence of $H$. pylori colonisation in tonsil and adenoid tissues. There was no significant relationship between recurrent adenotonsillitis and HP adenotonsillar colonisation. There was no difference between paediatric and adult patients with tonsillar illnesses in terms of the presence of $H$. pylori. However, it is difficult to establish generalisations about these topics due to the low incidence of $H$. pylori colonisation in our study.

Ethics Committee Approval: Çanakkale Onsekiz Mart Üniversitesi Tıp Fakültesi Local Committe.

Informed Consent: Informed Consent was taken from the all partpicants or parents.

Peer-review: Externally peer-reviewed.

Author contributions: Concept - O.G., A.A., M.T.O., F.S.D.; Design - O.G., A.A., M.T.O, F.S.D.; Supervision - O.G., A.A., M.T.O, F.S.D.; Resource - O.G., A.A., M.T.O, F.S.D.; Materials - O.G., A.A., M.T.O, F.S.D.; Data Collection\&/or Processing - O.G., A.A., M.T.O, F.S.D.; Analysis\&/or Interpretation - O.G., A.A., M.T.O, F.S.D, E.M.Ş, O.B, K.T; Literature Search - O.G., A.A., M.T.O, F.S.D, E.M.S.; Writing - O.G., A.A., M.T.O, F.S.D.; Critical Reviews - O.G., A.A., M.T.O, F.S.D.

Conflict of Interest: No conflict of interest was declared by the authors.

Financial Disclosure: This study was supported by the Scientific Research Department of Çanakkale Onsekiz Mart University.

\section{References}

1. Vilarinho S, Guimarães NM, Ferreira RM, Gomes B, Wen X, Vieira MJ, et al. Helicobacter pylori colonization of the adenotonsillar tissue: fact or fiction? Int J Pediatr Otorhinolaryngol 2010;74:807-11. [CrossRef]

2. Lin HC, Wu PY, Friedman M, Chang HW, Wilson M. Difference of Helicobacter pylori colonization in recurrent inflammatory and simple hyperplastic tonsil tissues. Arch Otolaryngol Head Neck Surg 2010;136:468-70. [CrossRef]

3. Cirak MY, Ozdek A, Yilmaz D, Bayiz U, Samim E, Turet S. Detection of Helicobacter pylori and its CagA gene in tonsil and adenoid tissues by PCR. Arch Otolaryngol Head Neck Surg 2003;129:1225-9. [CrossRef] 
4. Eyigor M, Eyigor H, Gultekin B, Aydin N. Detection of Helicobacter pylori in adenotonsillar tissue specimens by rapid urease test and polymerase chain reaction. Eur Arch Otorhinolaryngol 2009;266:1611-3. [CrossRef]

5. Jelavic B, Bevanda M, Ostojic M, Leventic M, Vasilj M, Knezevic E. Tonsillar colonization is unlikely to play important role in Helicobacter pylori infection in children. Int J Pediatr Otorhinolaryngol 2007;71:585-90. [CrossRef]

6. Vayisoglu Y, Ozcan C, Polat A, Delialioglu N, Gorur K. Does Helicobacter pylori play a role in the development of chronic adenotonsillitis? Int J Pediatr Otorhinolaryngol 2008;72:1497-501. [CrossRef]

7. Friedman $M$, Ibrahim $H$, Bass L. Clinical staging for sleep-disordered breathing. Otolaryngol Head Neck Surg 2002;127:13-21. [CrossRef]

8. Yilmaz T, Ceylan M, Akyön Y, Ozçakır O, Gürsel B. Helicobacter pylori: a possible association with otitis media with effusion. Otolaryngol Head Neck Surg 2006;134:772-7. [CrossRef]
9. Agirdir BV, Bozova S, Derin AT, Turhan M. Chronic otitis media with effusion and Helicobacter pylori. Int $\mathrm{J}$ Pediatr Otorhinolaryngol 2006;70:829-34. [CrossRef]

10. Minocha A, Raczkowski CA, Richards RJ. Is a history of tonsillectomy associated with a decreased risk of Helicobacter pylori infection? J Clin Gastroenterol 1997;25:580-2. [CrossRef]

11. Unver S, Kubilay U, Sezen OS, Coskuner T. Investigation of Helicobacter pylori colonization in adenotonsillectomy specimens by means of the CLO test. Laryngoscope 2001;111:2183-6. [CrossRef]

12. Bitar MA, Soweid A, Mahfouz R, Zaatari G, Fuleihan N. Is Helicobacter pylori really present in the adenoids of children? Eur Arch Otorhinolaryngol 2005;262:987-92. [CrossRef]

13. Yilmaz E, Doğan Y, Gürgöze MK, Unal S. Seroprevalence of Helicobacter pylori infection among children and their parents in eastern Turkey. J Paediatr Child Health 2002;38:1836. [CrossRef] 